\title{
Challenges and mental health needs of women in prison
}

Annie Bartlett and Sheila Hollins

\begin{abstract}
Summary
The world population of women and girls in prison is increasing. Evidence points to high rates of mental health problems. Approaches to these problems vary and include both psychiatric epidemiology and gender-sensitive understanding and intervention. Prison environments and women prisoners' needs are complex and demand gender-aware care in view of women's vulnerability and histories of trauma.
\end{abstract}

\section{Declaration of interest}

A.B. was a clinical director of the offender care services at Central and North West London National Health Service (NHS) Foundation Trust until August 2016, with responsibility for several women's prison healthcare services in London and the South East, and is currently clinical director of NHS England London Health in Justice Clinical Network, paid as a salary one day a week.

\section{Copyright and usage}

(c) The Royal College of Psychiatrists 2018.
Annie Bartlett (pictured) was, until August 2016, clinical director of the offender care services at Central and North West London National Health Service (NHS) Foundation Trust with responsibility for several women's prison healthcare services in London and the South East. She is currently clinical director of NHS England London health in the Justice Clinical Network. Sheila Hollins chaired an expert reference group for Health Education England from June 2015 to April 2017 reviewing the health and social care workforce for adults with intellectual disabilities and challenging behaviour.

This is an era of mass incarceration and women's imprisonment is significant and growing. The number of women and girls incarcerated worldwide has increased by half in the past 17 years; in total approximately $700000 .{ }^{1}$ There is international recognition that women in prison are very vulnerable. Mental ill health, notably substance misuse and post-traumatic stress disorder are common, alongside illiteracy, undiagnosed autism and intellectual disability. There are higher rates of self-harm and suicide when compared with male prisoners. ${ }^{2}$ The limited mental health services available are based either on current psychiatric diagnosis or gender-specific interventions. Both models operate within institutions where the primary purpose of the institution is not provision of healthcare but, at best, deprivation of liberty and rehabilitation.

\section{The context of confinement in the UK}

The recent focus on women offenders' vulnerability and trauma histories, as opposed to their criminality, has led to calls for more effective alternatives to custody in England and Wales, which are still awaited. The number of women in English prisons has stabilised at 16 per 100000 of the population in 2015 . Women constitute $5 \%$, a small but significant percentage, of the total prison population. In the last $3 / 4$ years the rate of death in custody for women has risen; 12 women died in 2016, the highest number since $2004 .^{3}$ Self-harm remains a major and resource-hungry problem, disproportionately affecting the women's prison estate: $50 \%$ of all selfharm incidents in prison are by women.

Both the fact of imprisonment and conditions of confinement have gender dimensions. In England and Wales prisons are less safe than 7 years ago with rising rates of assault. Women's deaths in custody are related to geographical dislocation, separation from children and family, bullying, loss of experienced staff, increased time in cells and reduced contact with personal officers, as well as unmet mental health and substance misuse needs. ${ }^{3}$ The government's commitment to improving conditions in custody and providing suitable community provision remains in doubt.

\section{Philosophies of care and treatment: gender neutrality and gender sensitivity}

This highly politicised arena has seen recent, local and international, gender-neutral recommendations for prison mental health and gender-sensitive interventions for women who offend.

The World Psychiatric Association's position statement devotes scant attention to female offenders but notes the particular needs of women offenders who are mothers and that women in prison may be at risk of sexual assault. The National Institute for Health and Care Excellence (NICE) guidelines on the mental health of adults in contact with the criminal justice system and The Royal College of Psychiatrists' prison quality standards contain minimal and no mention of gender-specific needs, respectively. NICE guidelines only recommend use of a mental health screening tool for women and include questions on pregnancy. The relative absence of women from these recent publications underlines the limited conceptual thinking about the mental health needs of women offenders.

It contrasts with the theoretical and practical focus on gender-specific needs internationally and locally in the past decade that have invoked key principles of equity and social justice in relation to healthcare. ${ }^{2}$ Recent initiatives in the UK and elsewhere, notably the USA, Canada and Australia, promote trauma-informed prisons for women offenders, ${ }^{4}$ for example One Small Thing (a training package for all prison staff on gender awareness). There are clear policy statements of gender-specific philosophies of healthcare. Diagnosable mental health problems within this gender-aware approach constitute only a final common pathway, leading from the multiple disadvantages and adversity disproportionately faced by women (a life spent in care, childhood trauma, trafficking, separation from dependent children, domestic violence and economic reliance on sex work). A gender-aware approach contrasts with conventional but robust epidemiological approaches to the nature and degree of psychiatric problems but is in line with the United Nations' unanimous endorsement of the Bangkok Rules that provide gender-specific guidance about many aspects of imprisonment (protection from violence, provision for children, rehabilitation) as well as healthcare. ${ }^{5}$

Support for gender-aware approaches comes from an emerging body of work establishing the risks of early experiences of sexual and physical violence and their links to later morbidity 
including major mental illness, substance misuse and post-traumatic stress disorder in women offenders. ${ }^{6}$ There is a developing evidence base for complex interventions for women offenders with multiple psychiatric morbidities, notably for those with histories of trauma and substance misuse. ${ }^{7}$ There have also been calls for a gendered understanding of the origins of offending and violence in women prisoners. Cross-cutting themes uniting this body of work are the prison as a potentially re-traumatising environment and the importance of autonomy and choice in women historically and contemporaneously stripped of both. This sits against a literature that is inconclusive as to whether or not imprisonment per se has a negative impact in women on measurable mental disorder.

\section{The validity of international perspectives}

Although the picture presented so far is in part parochial, it is far from clear whether an international approach to the care of women in prison is meaningful. Jurisdictions vary, the numbers and proportions of women in prison and the conditions and responses to confinement correspondingly differ. ${ }^{1}$ Having said that, it is true there is no jurisdiction where there are more women in prison than men. Rapidly rising rates of female incarceration internationally have attracted attention and challenge the status of current documentation about the mental health needs of those women incarcerated. A disproportionate number of publications come from the USA, which itself accounts for a third of all incarcerated women (approximately 200000 ). The only other countries with female prison populations of over 20000 are Brazil, Thailand, Vietnam, China and the Russian Federation (with virtually no mental health information available). It seems women in prison have higher rates of psychiatric morbidity than both men in prison and women in the community; experience multiple morbidity; report high rates of historical trauma and substance misuse and run the risk of poorly treated acute mental illness in custodial settings but caution is needed about how much is really known about much of the world.

There is particularly inadequate documentation about the additional vulnerabilities of poor social support, intellectual disability, autism, illiteracy, threats of deportation and linguistic exclusion that contribute to mental ill health and affect access to healthcare.

\section{Understanding the relevance of the prison world}

Prison healthcare is not delivered in a vacuum. Women prisoners' distinctive social worlds in prison mean they are more likely than men to maintain social contacts with children. The frequency and reasons for misconduct in prison differ by gender: women commit fewer prison rule violations. Histories of violent offending, mental illness and physical abuse are risks for men whereas isolation from external social support is a risk for women. Women prisoners also more often seek social support from prisoner activities. Many prison regimes, including those of the UK, were designed for more serious male offenders. Neither routine security practices nor the ethos of confinement were designed for women but have been imposed on them with scant regard for their lower level of offending or their gender-specific histories, needs, roles and values.

To be successful healthcare delivery needs to take into account not only women's social systems inside and outside the prison walls but also the detail of the particular criminal justice jurisdiction as applied to women. Jurisdiction-specific factors include the offence profile of women in prison and variable lengths of incarceration; ${ }^{8}$ options for prisoners with major mental illness, i.e. whether or not such illness warrants hospitalisation; processes to deal with complex needs such as a combination of disability and mental health problems; and the prison management of disruptive prisoners who may have underlying mental health difficulties including post-traumatic stress disorder, for example in California self-harm has been considered not a sign of distress but a rule violation. There is also variability in the age to which children accompanying imprisoned mothers can reside in prison, for example in India it is until the age of 6 years, in Indonesia it is 2 years; these children also have healthcare needs.

Prisons, at best, can be a resource for health gain. They may offer a relatively drug-free environment compared with the woman's normal circumstances (detoxification and psychosocial interventions), access to screening programmes (such as blood-borne viruses, cervical and breast cancer), exercise and the acquisition of life skills that can contribute to overall mental well-being and successful social reintegration.

The reasonable adjustments required by law in the UK (Equality Act 2010) to help disabled individuals applies to people with intellectual disability, autism and those with severe mental illness, not just those with physical disabilities. However, these impairments must be diagnosed correctly to ensure the right adjustments can be made during a period of incarceration, for example assistance with reading legal correspondence, protection from exploitation. ${ }^{9}$

\section{Principles of mental healthcare delivery}

The Kyiv declaration ${ }^{2}$ limits its recommendation to Europe, a system sufficiently well-resourced for screening, individualisedcare planning and primary and specialist healthcare to be possible. In the light of the emerging evidence base, paying attention to the gender dimensions of women's previous experience, the nature of the prison and the presence or absence of gender-specific factors that will help or hinder mental well-being seems wise. More internationally applicable, in that it derives from rights-based international agreements, may be an appeal for mental healthcare based on autonomy and self-determination. Lack of autonomy and self-determination underpin much mental distress, for example in Afghanistan 50\% of women in prison are there for 'moral crimes' such as running away from home or extra-marital sex, ${ }^{10}$ in the UK over half of imprisoned women report childhood victimisation. ${ }^{11}$ Although obviously culturally coded, a rightsbased approach may avoid the imposition of culturally insensitive healthcare on poorly described populations and allow for local solutions to develop.

This piece is written about women offenders not by them, although both their written and oral accounts can be vivid. Not to acknowledge this would be to be complicit with existing power structures in both prison and in psychiatry, which serve often to minimise choice, self-expression and self-direction, reinforcing women's existing difficulties born out of previous pre-prison experiences. This analytically critical power differential, itself often gendered, allows examination of the power and influence of professional talk and practice.

\section{Time to redefine the mental health task}

Women prisoners' distinctive early adverse experiences, their adult female social roles and often self-destructive ways of coping with demands and difficulties can combine to create gender-specific 
responses to imprisonment. Evidence supports working with women to address not only obvious mental illness but also trauma, social support needs, ongoing vulnerability and gendered patterns of offending to maximise the odds of a successful postrelease outcome. However, attending to the needs of women already incarcerated would be an inadequate response. Taking the long view will require attention to the root causes of women's distress, with particular attention to maternal mental health, the development of secure parent-infant attachments, safe environment training and universal relationships education. Early intervention following sexual trauma is needed as social care is failing these girls and women. Equally, the avoidance of women's imprisonment either by mental health options pre-imprisonment or by suitable community sentences for low-level offending would do much to avoid the perils of prison for women, with and without children. Some jurisdictions appear to achieve this; these models require greater scrutiny and replication.

Psychiatry alone offers too little, too late. The intractable, extreme problems presenting to prison mental health services demand clinical leadership for women's mental health services as part of a broader tapestry of care and support services. That leadership must go beyond the narrowly clinical if it is to contribute to effective services for women with multiple needs in complex and politically charged, clinical and carceral environments.

Annie Bartlett, MA (Cantab), MB BChir, PHD, MRCPsych, St George's University of London, London, UK; Sheila Hollins, MB, BS, FRCPsych, (Professor Emeritus in Psychiatry of Disability), St George's University of London, London, UK

Correspondence: Annie Bartlett, Professor of Offender Healthcare, St George's University of London, Cranmer Terrace, London SW17 ORE. Email: abartlet@sgul.ac.uk

First received 4 May 2017, final revision 04 Oct 2017, accepted 19 Nov 2017

\section{References}

1 Walmsley R. World Female Imprisonment List (3rd edn). World Prison Brief, 2015 (http://www.prisonstudies.org/sites/default/files/resources/downloads/ world_female_imprisonment_list_third_edition_0.pdf)

2 World Health Organisation. Women's Health in Prison: Correcting Gender Inequity in Prison Health. WHO, 2009 (http://www.euro.who.int/_data/assets/ pdf_file/0004/76513/E92347.pdf).

3 Independent Advisory Panel on Deaths in Custody. Preventing the Deaths of Women in Prison - Initial Results of a Rapid Information Gathering Exercise by the Independent Advisory Panel on Deaths in Custody. IAPDIC, 2017 (http:// iapdeathsincustody.independent.gov.uk/wp-content/uploads/2017/04/IAPrapid-evidence-collection-v0.2.pdf).

4 Bloom B, Owen B, Covington S. A Summary of Research, Practice, and Guiding Principles for Women Offenders. The Gender-Responsive Strategies Project: Approach and Findings. National Institute of Corrections, 2005.

5 United Nations Office on Drugs and Crime. United Nations' Rules for the Treatment of Women Prisoners and Non-Custodial Measures for Women Offenders with their Commentary. United Nations Office on Drugs and Crime, 2011.

6 Green BL, Dass-Brailsford P, Hurtado de Mendoza A, Mete M, Lynch SM DeHart DD, et al. Trauma experiences and mental health among incarcerated women. Psychol Trauma Theory Res Pract Policy 2016; 8: 455-63.

7 Bartlett A, Jhanji E, White S, Harty MA, Scammell J, Allen S. Interventions with women offenders: a systematic review and meta-analysis of mental health gain. Am J Forensic Psychiatry Psychol 2015; 26: 133-65.

8 United Nations Office on Drugs and Crime. Handbook on Women and Imprisonment. UNODC, 2008. (https://www.unodc.org/documents/justiceand-prison-reform/women_and_imprisonment_-_2nd_edition.pdf).

9 Hollins S, Giraud-Saunders A, Ryan M, Webb B, Ralls T. You're in Prison. Books Beyond Words, 2013.

10 United Nations Office on Drugs and Crime. Afghanistan Female Prisoners and their Social Reintegration. UNODC, 2007 (https://www.unodc.org/pdf/criminal_justice/Afghanistan_Female_Prisoners_and_their_Social_Reintegration.pdf).

11 Ministry of Justice. Prisoners' Childhood and Family Backgrounds. Ministry of Justice Research Series 4/12. Ministry of Justice, 2012. 